\title{
The Kanker Nazorg Wijzer (Cancer Aftercare Guide) protocol: the systematic development of a web-based computer tailored intervention providing psychosocial and lifestyle support for cancer survivors
}

Roy A Willems ${ }^{1 *}$, Catherine AW Bolman ${ }^{1}$, Ilse Mesters ${ }^{2}$, Iris M Kanera ${ }^{1}$, Audrey AJM Beaulen ${ }^{1}$ and Lilian Lechner ${ }^{1}$

\begin{abstract}
Background: After primary treatment, many cancer survivors experience psychosocial, physical, and lifestyle problems. To address these issues, we developed a web-based computer tailored intervention, the Kanker Nazorg Wijzer (Cancer Aftercare Guide), aimed at providing psychosocial and lifestyle support for cancer survivors. The purpose of this article is to describe the systematic development and the study design for evaluation of this theory and empirical based intervention.

Methods/design: For the development of the intervention, the steps of the Intervention Mapping protocol were followed. A needs assessment was performed consisting of a literature study, focus group interviews, and a survey study to get more insight into cancer survivors' health issues. This resulted in seven problem areas that were addressed in the intervention: cancer-related fatigue, return to work, anxiety and depression, social relationships and intimacy, physical activity, diet, and smoking. To address these problem areas, the principles of problem-solving therapy and cognitive behavioral therapy are used. At the start of the intervention, participants have to fill in a screening questionnaire. Based on their answers, participants receive tailored advice about which problem areas deserve their attention. Participants were recruited from November 2013 through June 2014 by hospital staff from 21 hospitals in the Netherlands. Patients were selected either during follow-up visits to the hospital or from reviews of the patients' files. The effectiveness of the intervention is being tested in a randomized controlled trial consisting of an intervention group $(n=231)$ and waiting list control group $(n=231)$ with a baseline measurement and follow-up measurements at 3, 6, and 12 months.
\end{abstract}

Discussion: Using the Intervention Mapping protocol resulted in a theory and evidence-based intervention providing tailored advice to cancer survivors on how to cope with psychosocial and lifestyle issues after primary treatment.

Trial registration: Dutch Trial Register NTR3375

Keywords: Cancer survivorship, eHealth, Quality of life, Psychosocial well-being, Lifestyle, Intervention Mapping, Computer tailoring, Problem-solving, Cognitive behavioral therapy

\footnotetext{
*Correspondence: roy.willems@ou.nl

${ }^{1}$ Faculty of Psychology and Educational Sciences, Open University of the Netherlands, P.O. Box 2960, 6401 DL Heerlen, The Netherlands

Full list of author information is available at the end of the article
} 


\section{Background}

With advances in cancer detection and treatment and an aging population the number of cancer survivors is increasing significantly [1]. It is well-known that survivors face a variety of difficulties and challenges after treatment, such as anxiety, depression, fear of recurrence, fatigue, pain, physical and cognitive limitations, difficulties with employment, and sexual dysfunctions [2-9]. These issues can have a negative impact on quality of life $[8,9]$ and may continue long after treatment has ended [10]. Cancer patients experience a peak level of distress within the first year after treatment, which might be partially explained by loss of security associated with being in treatment and loss of regular contact with health professionals [11]. Moreover, having a healthy lifestyle expedites recovery and, therefore, is of special importance for survivors. However, many survivors do not have a healthier lifestyle than people without a history of cancer [12]: more than half are overweight, less than half comply with physical activity recommendations, only one fifth adheres to fruit and vegetable recommendations, and one in ten smokes [13-16].

More than half of the survivors report having unmet information and support needs on how to deal with issues such as emotional and social support, fear and stress, and treatment and follow-up care [17-20]. Concerning lifestyle, survivors express a need for information and support regarding increasing exercise, improving diet, and smoking cessation [20-22]. To improve the aftercare for cancer survivors, a national guideline for cancer survivorship care was developed in the Netherlands [23]. This guideline describes the importance of a broad programmatic approach for oncology aftercare in which selfmanagement should be stimulated.

The Internet has become a key source for health-related information for cancer survivors [24-26] and has the potential to fill an important gap in cancer care [27]. A great advantage of web-based interventions is that they can reach many patients at once and are accessible anytime and anywhere [28]. However, due to the broad variety of difficulties experienced and the different characteristics of the survivors, it is challenging to provide individually relevant information and support [20]. By means of computer tailoring, information and support can be provided that is adapted to the individual's needs and characteristics, while still reaching large groups.

To provide cancer survivors personalized information and support and stimulating self-management during life after cancer, we developed the web-based computer tailored intervention the Kanker Nazorg Wijzer (Cancer Aftercare Guide; KNW). To increase the likelihood of reaching intervention effectiveness, the Intervention Mapping (IM) protocol was used [29]. This is a systematic, theoretical and empirical-based approach for intervention development. In this article, the development of the KNW according to the steps of IM and the evaluation of the intervention's effectiveness is described.

\section{Methods/design}

The IM protocol consists of six steps [29]: (1) a needs assessment of the study population, (2) specification of performance objectives and crossing them with relevant determinants into change objectives, (3) selecting theoryinformed intervention methods and practical applications to change the determinants of the health behavior, (4) producing and pretesting program materials, (5) planning program adoption and implementation, and (6) planning for evaluation.

\section{Step 1: Needs assessment}

In the needs assessment, the health problem and its impact on the quality of life of the at-risk group is assessed [29]. Understanding cancer survivors' experienced problems and information and support needs is a crucial step in designing interventions that meet survivors' needs [30]. Since it was clear that an overall problem among cancer survivors is a reduced quality of life [8,9], the following program goal was stated: At six and twelve months after the start of the KNW program, cancer survivors will report an increased quality of life. The needs assessment aimed to disclose which problem areas should be addressed to achieve this goal.

We conducted a needs assessment consisting of a literature study, focus group interviews, and a survey. The literature provided an overview of cancer survivors' health-related problems. Anxiety and depression [31], fear of recurrence [3], fatigue [4], sleep problems [32], difficulties concerning return to work [5], pain [33], and sexual dysfunction [34, 35] are frequently identified problems. Furthermore, a healthy lifestyle is associated with positive health outcomes in cancer survivors, while unhealthy lifestyle behaviors may lead to the development of other chronic diseases, new primary tumors, and cancer recurrence [36-39]. Unfortunately, a large proportion of cancer survivors do not adhere to recommendations concerning physical activity, dietary, and smoking behavior [13, 40].

Then, we conducted six focus group interviews with 33 cancer survivors using a predefined protocol [41]. The topics discussed included experienced problems during survivorship and aftercare needs. Most survivors indicated that they did not know what to expect after treatment or how to cope with their experienced problems. Commonly indicated problems included pain, fear of recurrence, fatigue, concentration problems, insomnia, sadness, insecurity, dealing with social relationships, and work related problems. Many survivors reported difficulties in adhering to physical activity and diet recommendations. However, physical activity was seen as an important contributor to 
recovery. Furthermore, many survivors indicated that they did not always know where they could get aftercare or that the aftercare was not easy accessible. Most survivors expressed the need for more attention from the hospital staff to their psychological, physical, and lifestyle issues. Moreover, the information provided by hospitals concerning aftercare possibilities was described as insufficient. The information on the Internet was described as cluttered and bulky.

Finally the prevalence and correlates of unmet information and support needs and healthy lifestyle behaviors were investigated in a survey conducted among 255 cancer survivors within the first year after their primary treatment $[20,42]$. The results indicated that almost two-thirds of the survivors reported having unmet needs. Frequently cited unmet needs concerned emotional and social support, help to deal with fear of recurrence, management of healthcare and complications, up-to-date information, management of return to work, increasing exercise, and help to quit smoking. While help to eat healthier was not a frequently mentioned unmet need [20], adherence to fruit and vegetable recommendations was poor [42]. High education, having breast cancer, participation in support programs, low quality of life, high levels of anxiety, and a more negative adjustment to cancer were associated with having more unmet needs in general [20]. Self-efficacy, attitude, and intention were the strongest correlates of lifestyle behaviors [42].

\section{Step 2: Matrices of change objectives}

Step 2 provides the foundation of the intervention by specifying what will change as a result of the intervention [29]. For this purpose, performance objectives (POs) are formulated. These are statements of what the program participants need to do to perform the intended healthpromoting behavior. Then, important and changeable determinants for the POs are selected. This is necessary for creating change objectives (COs). COs specify what changes in the determinants are needed to make the attainment of the POs most likely.

To specify POs, it needs to be clear what the program outcome should be (i.e. what the program aims to achieve). Based on the needs assessment, the focus of the program was set to significantly reduce experienced problems in seven areas, namely (1) cancer related fatigue, (2) difficulties concerning return to work, (3) anxiety and depression, (4) social relationship and intimacy issues, (5) a lack of physical activity, (6) a lack of healthy food intake, and (7) difficulties in preparing or maintaining smoking cessation. By effectively managing these problems, improved outcomes in these problem areas are expected, ultimately resulting in a better quality of life.
Several POs were formulated for each problem area. An example of a PO for the program outcome "Reduce cancer-related fatigue" is "Say 'no' to a request when it is too much to handle" (see Table 1). Then, the most important and changeable behavioral determinants of the POs were selected from theory and literature. The most relevant determinants differed for each problem area. For example, relevant determinants for reducing cancer-related fatigue included knowledge, awareness, attitude, skills, self-efficacy, perceived behavior of others, and outcome expectations. Relevant determinants of engagement in sufficient physical activity included attitude, self-efficacy, social support, and perceived barriers. Next, COs were stated. Examples of COs for the PO "Say 'no' to a request when it is too much to handle" were "Describe steps to undertake to effectively say 'no' to others" (knowledge) and "See fellow survivors acknowledging the importance of saying 'no' to others" (perceived behavior of others) (see Table 2).

\section{Step 3: Selecting theoretical methods and practical applications}

In this step theoretical methods and practical applications for achieving the COs and POs are selected [29]. A theoretical method is a technique or process for influencing change in the determinants of the targeted behavior. A

Table 1 Performance objectives for the program outcome "Reduce cancer-related fatigue"

\section{PO 1 Manage daily tasks efficiently}

PO 1.1 Alternate mental and physical activities

PO 1.2 Take small moments of rest divided over the day

PO 1.3 Take adequate measures so not to exceed personal limits

PO 1.4 Say "no" to a request when it is too much to handle

PO 1.5 Make a structured plan of daily activities

PO 2 Turn non-helpful thoughts about fatigue into helpful thoughts

PO 2.1 Recognize common non-helpful thoughts about fatigue

PO 2.2 Identify personal non-helpful thoughts

PO 2.3 Generate helpful thoughts

PO 2.4 Replace non-helpful thoughts with helpful thoughts

PO 2.5 Implement personal strategies to cope with rumination

PO 2.6 Use relaxation or mindfulness techniques

PO 3 Take sleep hygiene measures

PO 3.1 Identify the type of sleeping problem one is experiencing

PO 3.2 Go to bed and get out of bed at set times every day of the week

PO 3.3 Take care of optimal sleeping conditions

PO 3.4 Identify behaviors that interfere with sleep and replace these with helpful behaviors

PO 3.5 Use relaxation or mindfulness techniques 
Table 2 Matrix of change objectives for the performance objective "Manage daily tasks efficiently"

\begin{tabular}{|c|c|c|c|c|c|c|}
\hline $\begin{array}{l}\text { Reduce cancer- } \\
\text { related fatigue }\end{array}$ & Knowledge & Awareness & Attitude & Skills and Self-Efficacy & $\begin{array}{l}\text { Perceived Behavior of } \\
\text { Others }\end{array}$ & Outcome Expectations \\
\hline $\begin{array}{l}\text { PO.1. Manage daily } \\
\text { tasks efficiently }\end{array}$ & & $\begin{array}{l}\text { Aw.1. Become aware of } \\
\text { planning and structure } \\
\text { of own daily activities }\end{array}$ & $\begin{array}{l}\text { At.1. Feel positive } \\
\text { about reorganizing } \\
\text { daily activities }\end{array}$ & $\begin{array}{l}\text { SSE.1. Feel confident about } \\
\text { managing daily activities }\end{array}$ & $\begin{array}{l}\text { PBO.1. See fellow } \\
\text { survivors } \\
\text { acknowledging the } \\
\text { importance managing } \\
\text { daily activities }\end{array}$ & $\begin{array}{l}\text { OE.1. Expect that managing } \\
\text { daily tasks efficiently can } \\
\text { reduce feelings of fatigue }\end{array}$ \\
\hline \multirow[t]{2}{*}{$\begin{array}{l}\text { PO.1.1. Alternate } \\
\text { mental and physical } \\
\text { activities }\end{array}$} & $\begin{array}{l}\text { K.1a. Describe the } \\
\text { importance of alternating } \\
\text { mental and physical activities }\end{array}$ & \multirow{2}{*}{$\begin{array}{l}\text { Aw.2. Become aware whether } \\
\text { mental and physical activities } \\
\text { are alternated in own daily } \\
\text { scheme }\end{array}$} & & & & \multirow[t]{2}{*}{$\begin{array}{l}\text { OE.2. Expect that alternating } \\
\text { mental and physical activities } \\
\text { can reduce experiences of fatigue }\end{array}$} \\
\hline & $\begin{array}{l}\text { K.1b. Recall advice on } \\
\text { alternating activities }\end{array}$ & & & & & \\
\hline \multirow[t]{2}{*}{$\begin{array}{l}\text { PO.1.2. Take small } \\
\text { moments of rest } \\
\text { divided over the day }\end{array}$} & $\begin{array}{l}\text { K.2a. Describe the } \\
\text { importance of taking small } \\
\text { moments of rest }\end{array}$ & \multirow[t]{2}{*}{$\begin{array}{l}\text { Aw.3. Become aware whether } \\
\text { daily rest is divided in small } \\
\text { moments over the day }\end{array}$} & & & & \multirow{2}{*}{$\begin{array}{l}\text { OE.3. Expect that taking small } \\
\text { moments of rest divided over the } \\
\text { day can reduce experiences of } \\
\text { fatigue }\end{array}$} \\
\hline & $\begin{array}{l}\text { K.2b. Recall advice on } \\
\text { taking rest }\end{array}$ & & & & & \\
\hline \multirow{2}{*}{$\begin{array}{l}\text { PO.1.3. Take } \\
\text { adequate measures } \\
\text { to not exceed personal } \\
\text { limits }\end{array}$} & $\begin{array}{l}\text { K.3a. Recall possible signals } \\
\text { of exceeding personal limits }\end{array}$ & & \multirow{2}{*}{$\begin{array}{l}\text { At.2. Feel positive } \\
\text { about guarding } \\
\text { personal boundaries }\end{array}$} & \multirow{2}{*}{$\begin{array}{l}\text { SSE.2. Feel confident about } \\
\text { recognizing signals and taking } \\
\text { adequate measures }\end{array}$} & \multirow{2}{*}{$\begin{array}{l}\text { PBO.2. See fellow } \\
\text { survivors } \\
\text { acknowledging the } \\
\text { importance of not } \\
\text { exceeding personal } \\
\text { limits }\end{array}$} & \multirow{2}{*}{$\begin{array}{l}\text { OE.4. Expect that taking adequate } \\
\text { measures when exceeding limits } \\
\text { can reduce experiences of fatigue }\end{array}$} \\
\hline & $\begin{array}{l}\text { K.3b. Recall effective } \\
\text { measures when exceeding } \\
\text { limits }\end{array}$ & & & & & \\
\hline $\begin{array}{l}\text { PO.1.4. Say "no" to a } \\
\text { request when it is too } \\
\text { much to handle }\end{array}$ & $\begin{array}{l}\text { K.4. Describe steps to } \\
\text { undertake to effectively say } \\
\text { "no" to others }\end{array}$ & & $\begin{array}{l}\text { At.3. Feel positive } \\
\text { about saying "no" } \\
\text { to others }\end{array}$ & $\begin{array}{l}\text { SSE.3. Feel confident about } \\
\text { saying "no" to others }\end{array}$ & $\begin{array}{l}\text { PBO.3. See fellow } \\
\text { survivors } \\
\text { acknowledging the } \\
\text { importance of saying } \\
\text { "no" to others }\end{array}$ & $\begin{array}{l}\text { OE.5. Expect that others generally } \\
\text { accept when receiving "no" to a } \\
\text { request }\end{array}$ \\
\hline $\begin{array}{l}\text { PO.1.5. Make a } \\
\text { structured plan of daily } \\
\text { activities }\end{array}$ & $\begin{array}{l}\text { K.5. Summarize advice on } \\
\text { making a structured plan }\end{array}$ & & & $\begin{array}{l}\text { SSE.4. Demonstrate ability of } \\
\text { making an efficient plan by } \\
\text { incorporating advice in the } \\
\text { new plan }\end{array}$ & & $\begin{array}{l}\text { OE.6. Expect that making a new } \\
\text { plan will help in dealing with } \\
\text { fatigue }\end{array}$ \\
\hline
\end{tabular}


practical application is a specific technique for practical use of a theoretical method. For example, by means of selfmonitoring of behavior (method) we aimed to change cancer survivors' awareness of how they scheduled their daily activities (determinant) by encouraging them to register their daily activities for five to seven days (practical application) (see Table 3). Methods and applications were derived from literature, focus group interviews, and existing interventions (see Step 4, Reviewing available materials).

Several methods were used in the KNW such as feedback, personalizing risk, consciousness raising, belief selection, modeling, active learning, persuasive communication, argumentation, goal setting, action planning, and implementation intentions. Two methods formed the core of the KNW: tailoring and skills training for self-management. These two methods were used throughout the entire intervention and were combined with the other methods to change the determinants of the targeted behaviors.

\section{Tailoring}

Tailoring is a technique in which information is provided that is adapted to the personal characteristics circumstances, beliefs, motivations, and behavior of the receiver $[43,44]$. Thus, by means of tailoring, personalized advice can be provided that suits the cancer survivors' needs. Overall, tailoring is proven to be an effective technique in health promotion and communication [43, 45-48]. Since the information is personalized, less redundant information is provided, attention is increased, information is more thoughtfully processed, and behavior change or maintenance is better facilitated $[43,44,49,50]$. The $\mathrm{KNW}$ starts with a screening questionnaire that enables tailoring. Based on their answers, participants receive feedback about which of the seven problem areas deserve their attention (see also Step 4, Screening questionnaire). When selecting a problem area that the participant wants to work on, the information on that problem is tailored further, eventually resulting in a personalized action plan.

\section{Skills training for self-management}

Self-management is an iterative process that comprises observation of one's behavior (monitoring) making judgments of behavior based on the observation (evaluation), setting goals, and choosing and applying strategies to achieve these goals (action) $[29,51,52]$. The principles of problem-solving therapy (PST) $[53,54]$ and cognitive behavioral therapy (CBT) [55] were used as applications to increase cancer survivors' self-management skills. PST and CBT for cancer patients and survivors have been found effective for, amongst others, improving symptom management $[56,57]$, mental health and quality of life $[58,59]$, dealing with uncertainty [57], fatigue [60-62] and insomnia [63], and reducing psychological distress [64, 65].

PST comprises five steps in which the patient (1) needs to adopt a positive attitude towards facing the problem, (2) defines what the problem exactly is, (3) makes a list of

Table 3 Methods and applications to change the determinants of the performance objective "Manage daily tasks efficiently"

\begin{tabular}{|c|c|c|}
\hline Determinant & Theoretical methods & Practical applications \\
\hline \multirow[t]{3}{*}{ Knowledge } & Chunking & $\begin{array}{l}\text { Advice provided is divided in several topics and is summarized when participants } \\
\text { make their own planning. }\end{array}$ \\
\hline & Elaboration & $\begin{array}{l}\text { After providing advice, personally relevant messages encourage participants to } \\
\text { incorporate this advice with their situation. }\end{array}$ \\
\hline & Cues & $\begin{array}{l}\text { Cues are provided that help saying "no" to a request and to recognize when personal } \\
\text { limits are exceeded. }\end{array}$ \\
\hline \multirow[t]{2}{*}{ Awareness } & Consciousness raising & \multirow{2}{*}{$\begin{array}{l}\text { Cancer survivors are encouraged to register their daily activities for five to seven days. } \\
\text { After registration, survivors are given advice on effectively planning their day, asked to } \\
\text { compare their plan with the advice received, and encouraged to adjust their plan to } \\
\text { meet this advice. }\end{array}$} \\
\hline & Self-monitoring of behavior & \\
\hline Attitude & Arguments & $\begin{array}{l}\text { Cancer survivors are given arguments why efficiently planning daily activities is } \\
\text { beneficial for reducing fatigue, why guarding personal boundaries is important, } \\
\text { and why saying "no" to some requests is important. }\end{array}$ \\
\hline \multirow[t]{3}{*}{ Skills and Self-Efficacy } & Active learning & Cancer survivors are encouraged to make their own weekly plan using the advice given. \\
\hline & \multirow[t]{2}{*}{ Action planning } & $\begin{array}{l}\text { Cancer survivors are encouraged to make a list of personal signals indicating that limits } \\
\text { are exceeded and select adequate measures for each signal. }\end{array}$ \\
\hline & & $\begin{array}{l}\text { Cancer survivors are encouraged to make their own action plan for when they are in a } \\
\text { situation in which they want to say "no" to a request. }\end{array}$ \\
\hline $\begin{array}{l}\text { Perceived Behavior } \\
\text { of Others }\end{array}$ & Modeling & $\begin{array}{l}\text { Cancer survivors are provided with narratives of other survivors who are further along in } \\
\text { their recovery process. In these narratives the importance and effectiveness of planning } \\
\text { daily activities, setting personal boundaries, and saying "no" to others is explained. }\end{array}$ \\
\hline \multirow[t]{3}{*}{ Outcome Expectations } & Persuasive communication & \multirow{3}{*}{$\begin{array}{l}\text { By providing information from different sources (e.g., peers) on managing daily activities } \\
\text { and by making assignments, cancer survivors are encouraged to expect that fatigue can } \\
\text { be dealt with when taking adequate measures. }\end{array}$} \\
\hline & Active learning & \\
\hline & Modeling & \\
\hline
\end{tabular}


alternatives to tackle the problem, (4) predicts the benefits and consequences of each alternative, and (5) implements the best alternative in daily life and evaluates the result [53]. In the KNW, each problem area is addressed following the structure of PST; that is, identifying the problem and selecting a goal, getting informed of different solutions, making a personalized action plan, and trying out the action plan and evaluating the progress.

The basic principles of CBT are covered by providing psycho-education and giving assignments such as monitoring behavior or thoughts, challenging dysfunctional cognitions, and encouraging patients to set new goals. In addition, elements were used from a treatment protocol proven effective for treating cancer-related fatigue among cancer survivors [55]. The protocol links six factors to fatigue: (1) poor coping with cancer, (2) fear of cancer recurrence, (3) dysfunctional cognitions, (4) dysregulation of sleep, (5) dysregulation of activity, and (6) low social support. All these factors are addressed in the KNW.

\section{Step 4: Producing program components and materials}

With the end products of the previous steps, the program components and materials were produced. This included describing the program scope and sequence, preparing design documents, reviewing available materials, and developing and testing the program materials [29].

\section{Scope and sequence}

The KNW (http://www.kankernazorgwijzer.nl) covers seven self-management training modules. The modules Fatigue, Return to Work, Mood (i.e. anxiety and depression), and Relationships mainly cover psychosocial and mental health related issues, while the modules Physical
Activity, Diet, and Smoking cover lifestyle-related issues. The modules are interrelated. For example, within the Fatigue module, participants receive the advice to also visit the Physical Activity module if there is an indication that the participant is getting too little physical activity. As discussed in Step 3, the sequence within the modules is based on PST [53]. In general, the modules consist of four components divided over two sessions. In the first session, participants identify their problem, select a goal and receive psycho-education and assignments on how to deal with their problem, and personalize their goal through action plans. After thirty days, participants are invited for a second session in which they can evaluate the progress of their goal. If successful, participants are encouraged to maintain their behavior. Otherwise, participants are encouraged to try again, try another solution, or adjust their goal and receive additional advice on how to deal with difficult situations. Furthermore, all modules provide links to other relevant and reliable websites.

Participants of the focus groups (see Step 1) expressed the need to be informed about commonly experienced complaints after cancer treatment. Therefore, an additional module covering residual symptoms from cancer treatment was added to the KNW. In this module, general information is given on the most common physical complaints experienced after primary treatment, tips are given on how to deal with these symptoms, and advice is given to seek medical assistance for more information or help. For an overview of the scope and sequence of all modules, see Fig. 1.

To keep participants involved in the program several types of e-mails were sent. First, participants received reminder e-mails when they completed the screening

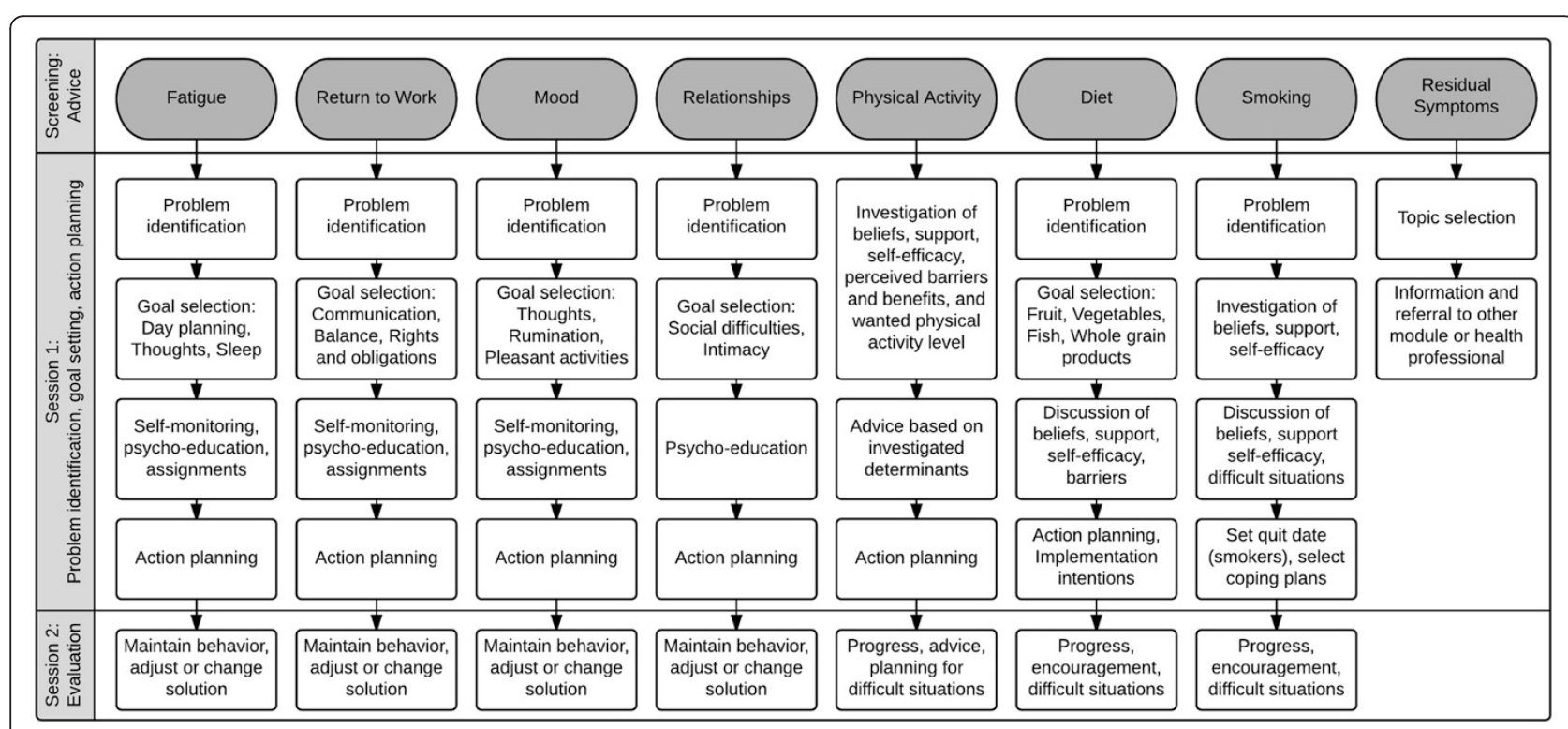

Fig. 1 Overview of the scope and sequence of the modules 
questionnaire but did not visit any of the modules. Second, participants received an e-mail to invite them to the second session of a module. Third, participants received a postcard in spring wishing them Happy Easter and an eCard around the Holidays wishing them Happy Holidays. Fourth, monthly news items were placed on the website in which professionals from different fields talk about cancer recovery (see Step 4, Video material). Participants received an invitation e-mail to see the latest news item.

\section{Suggestions from the target group}

During the focus group interviews (see Step 1), the preferences for the look and feel of the future program were discussed. First, survivors suggested messages to be framed positively and that the program should have a calm and friendly appearance (see Fig. 2). Second, survivors indicated that they preferred an open and unrestrictive program. Therefore, the KNW is programmed in such a way that users can choose which modules of the intervention they want to follow, even if they get the advice that they are doing well in this area. Third, survivors mentioned that the intervention should be easy to use. Therefore, a website with clear and distinctive buttons was designed with an emphasis on preventing an overload of information. Finally, it was suggested that the written information should be supported with video material. We adhered to this by providing informational videos from professionals from different fields. Also, there was a high demand for videos of fellow survivors, who were further into their recovery process, discussing their experiences of their life after cancer treatment. Therefore, we interviewed eight former patients discussing their cancer recovery and giving advice on how to deal with certain issues (see Step 4, Video material).

\section{Reviewing available materials}

Before developing the program materials, available program materials of others were reviewed for a possible match with the COs, methods, and applications of the KNW [29]. There were some computer tailored interventions from which elements were usable for the modules of the KNW. For the Physical Activity module, we shortened and adjusted the Active Plus intervention [66-69] to meet the characteristics of our target group. We also used elements from computer tailored interventions on smoking cessation [70-72] and nutrition [73-77]. As mentioned in Step 3, the Fatigue module was based on a protocol for treating cancer-related fatigue [55].

\section{The intervention}

Screening questionnaire. The KNW starts with a screening questionnaire measuring several concepts, including

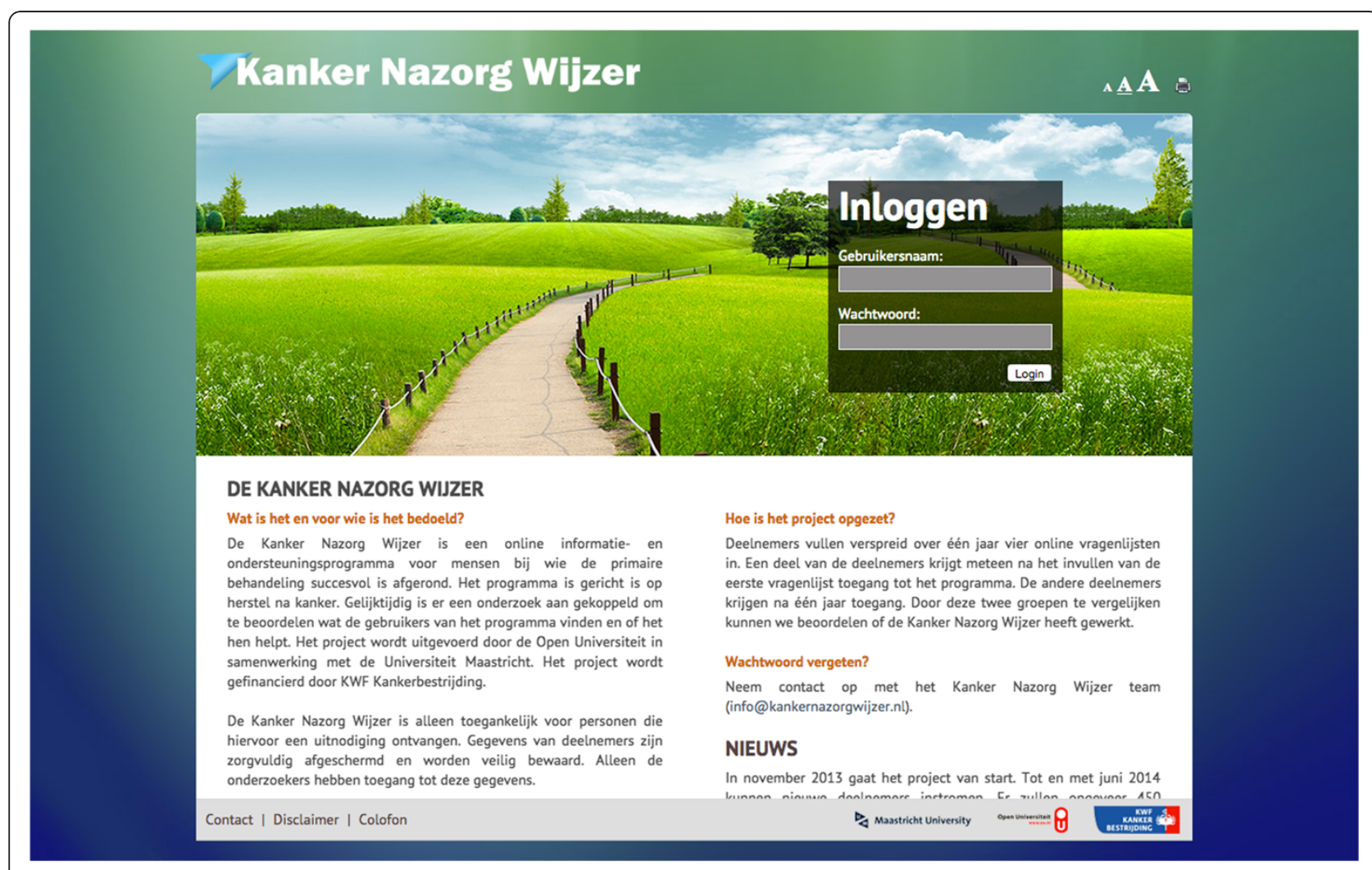

Fig. 2 The appearance of the KNW 
fatigue, work limitations, psychological distress, social support, physical activity, food intake, and smoking behavior (see Step 6, Measurements). Based on their answers, participants receive personal advice about which modules deserves their further attention. For this, a thermometer is used as visual aid (see Fig. 3). "Green" advice indicates that the participant is doing well in this area and visiting the corresponding module is not necessary. "Orange" advice indicates that the participant is doing reasonably well, but there still is room for improvement. "Red" advice indicates that the participant is strongly advised to visit the corresponding module.

\section{Modules}

Fatigue. In the Fatigue module, cancer-related fatigue is addressed. Based on the answers of the screening questionnaire, participants receive a description of the type of fatigue they are most likely experiencing. Participants receive an improvement proposal, comprising the themes day plan, fatigue-related thoughts, sleeping behavior, feelings of anxiety or depression, relationships, and physical activity. When participants want to work on physical activity, relationships, or feelings of anxiety and depression, they are referred to the Mood, Relationships, and Physical Activity modules, respectively.
The theme "Day Plan" discusses the importance of a structured day plan. Participants are encouraged to monitor their daily activities for five to seven days. Then, psychoeducation and assignments are given concerning planning activities and rest, not to exceed personal limits, and saying "no" to requests. Finally, participants are encouraged to make a weekly plan.

The theme "Thoughts About Fatigue" discusses beliefs concerning fatigue that are fatigue enhancing. Psychoeducation and assignments are given on recognizing and identifying non-helpful thoughts. Participants are encouraged to register their own non-helpful thoughts for one week. Then, these thoughts are challenged by discussing their credibility and usefulness and advice is given on how to replace these thoughts with helpful thoughts. Furthermore, advice is given on how to deal with rumination. Finally, to deal with stress related to dysfunctional cognitions, information and assignments are given concerning relaxation and mindfulness.

The theme "A Good Night's Sleep" discusses participants' sleeping behavior. Participants are encouraged to monitor their sleep and wake times for one week. Then, psycho-education and assignments are given concerning types of sleeping problems, the importance of a consistent sleep-wake pattern, and sleeping hygiene.

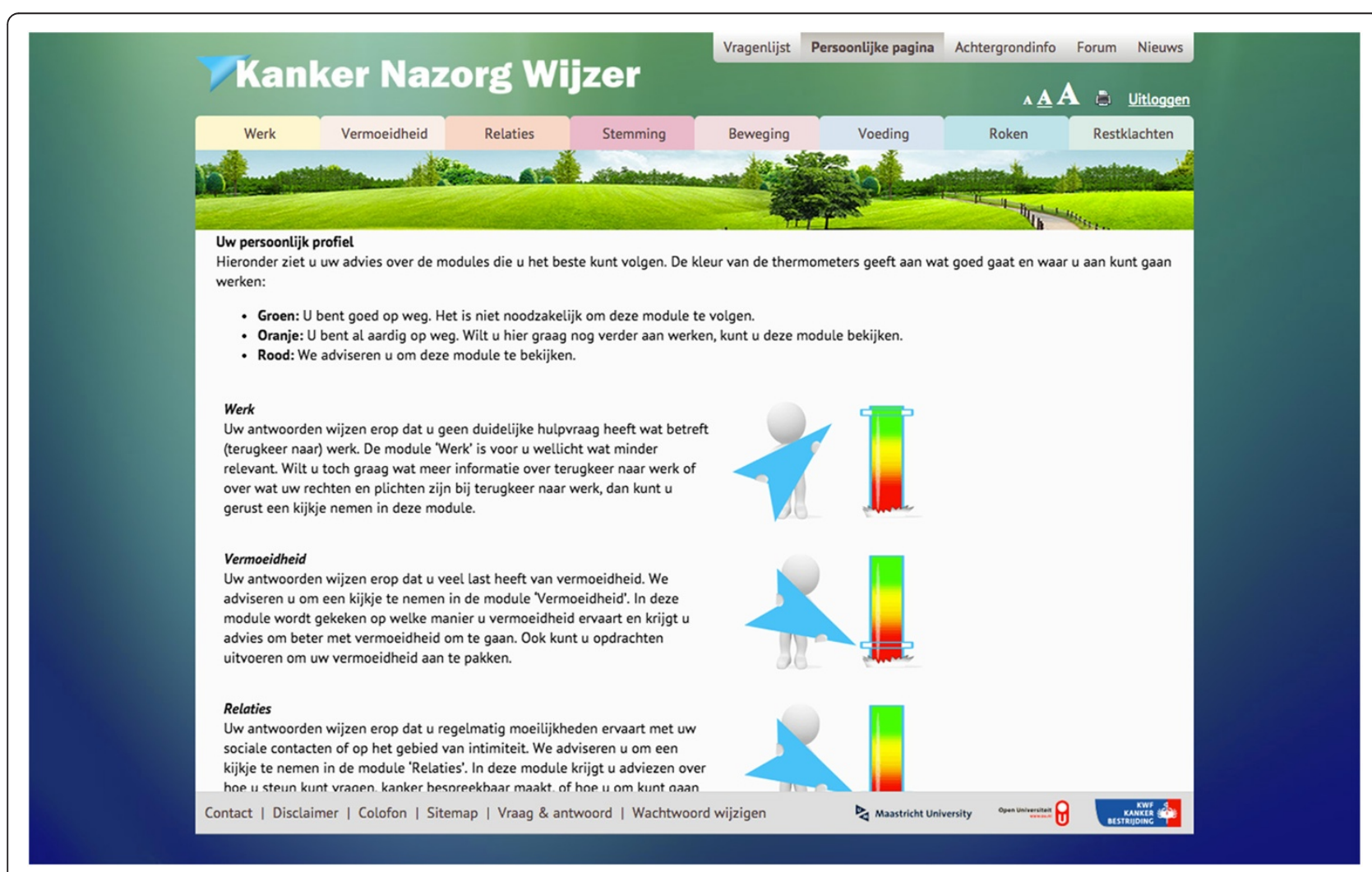

Fig. 3 After screening, participants are advised which module deserve their attention 
Also, information and assignments are given concerning relaxation and mindfulness.

Return to Work. In the Return to Work module, difficulties and rights and obligations concerning returning to work are discussed. Based on the answers of the screening questionnaire, participants receive an overview of their indicated problems concerning return to work and are given the opportunity to further specify these problems. Then, participants select a goal that they want to achieve (e.g., learning to ask for help). Depending on the chosen goal, participants are advised to continue with one of the three themes: Communication, Balance, and Rights and Obligations.

The theme "Communication" discusses the preparation of difficult work-related conversations. Psycho-education and assignments are given on preparing work-related conversations with different persons, such as one's occupational physician, supervisor, or colleague. Advice is given on, amongst others, how to indicate possibilities and limitations with regard to work tasks, asking for help, dealing with incomprehension from the manager or colleagues, or preparing a job application. Moreover, advice and assignments are given on how to increase feelings of confidence and decrease feelings of stress in difficult interactions.

The theme "Balance" focuses on finding a balance between the participants' work abilities and their workload. Participants are encouraged to monitor for several workdays how much energy certain work-related tasks cost. Then, psycho-education and assignments are given concerning planning the workday, not to exceed personal limits, making adjustments at work, dealing with limited concentration and memory problems, relaxation, and thinking positively.

The theme "Rights and Obligations" provides information on cancer survivors' rights and obligations concerning work with a long-term illness. Information is provided on topics such as re-integration unemployment, searching for a new job, social welfare payments, insurances, legal advice, or rights on facilities to perform one's job properly, given the limitations caused by the disease or treatment.

Mood. The Mood module focuses on feelings of anxiety and depression. More specifically the module discusses common anxiety and depression provoking thoughts and how to cope with these thoughts more effectively. Based on the answers of the screening questionnaire, participants receive feedback on their current state of anxiety, depression, and adjustment to cancer. When there is an indication that the participant is experiencing severe levels of psychological distress, a recommendation is given to visit one's general practitioner to get a referral for help. In the module, participants first set a goal they want to achieve (e.g., to reduce feelings of sadness). Then, psycho- education and assignments are given concerning nonhelpful or anxiety provoking thoughts, such as feelings of failure or fear of cancer recurrence. Participants are encouraged to monitor their inefficient thoughts for one week. Then, these thoughts are challenged by discussing their credibility and usefulness and advice is given on how to replace these thoughts with helpful thoughts. Furthermore, advice and assignments are given concerning planning pleasant activities, how to deal with rumination, and how to reduce feelings of anxiety or sadness by means of relaxation and mindfulness.

Relationships. The Relationships module addresses coping with difficult social situations and intimacy problems. Difficult social situations are discussed, such as receiving inadequate help from others, social isolation, experiencing social pressure, and talking about having had cancer. Based on the answers of the screening questionnaire, participants receive an overview of social situations in which they wish change. After selecting such a social situation, psycho-education is given on how to constructively deal with this situation.

Concerning intimacy, psycho-education is given on discussing intimacy and sexuality with significant others and how to cope with sexuality with respect to physical and functional changes due to cancer treatment. Coping with physical and functional changes is tailored to gender. For example, men receive information on how to cope with issues such as erectile dysfunction or dry orgasms, while for women advice is given on how to cope with issues such as menopausal symptoms or vaginal problems.

Physical Activity. In the Physical Activity module, participants are encouraged to increase their level of physical activity. Based on the answers of the screening questionnaire in combination with the Dutch physical activity guidelines, participants receive feedback on their own level of physical activity and to which extent it reaches the recommended level. Then, participants are encouraged to set a goal, for example, increasing physical activity during commuting, daily activities, leisure time, or sports. Subsequently, advice is given based on the participant's beliefs about the pros and cons of exercising, perceived barriers and benefits, self-efficacy, and social support. Next, participants are encouraged to make a personal exercise plan. The module provides information on specific exercises and sport activities tailored to participant's individual situation, physical limitations and social cognitive determinants.

Diet. The Diet module focuses on increasing fruit, vegetables, whole grain bread, and fish consumption. Based on the answers of the screening questionnaire in 
combination with the Dutch nutritional guidelines, participants receive feedback on their dietary habits and the extent to which it reaches the recommended level. The module subsequently provides a standard, nonpersonalized overview of a healthy diet, including desirable and undesirable foods and an indication of the recommended servings. Afterwards participants are encouraged to set one or two goals, for example, eating two pieces of fruit per day or eating 200 grams of vegetables per day. Subsequently, dietary advice is given, personalized to the participant's individual situation, experienced medical or treatment related problems, and the participant's attitudes, self-efficacy, and social support toward performing the desired dietary behavior.

Smoking. The Smoking module is developed for smokers to stimulate them to refrain from smoking and for former smokers to prevent relapse. Based on the answers of the screening questionnaire, participants' current smoking behavior is discussed. Smokers are encouraged to quit and to set a quit date. Advice is given on how to anticipate risky situations for a lapse and how to deal with withdrawal symptoms. Smokers are encouraged to develop an individual coping plan to prepare their quit attempt and to deal with difficult moments to maintain abstinence. Former smokers also receive advice based on their individual situation and social cognitive determinants, aimed at the prevention of relapse. They are also encouraged to develop coping strategies to prevent relapse.

Residual Symptoms. In the Residual Symptoms module, brief information is given about complaints, such as pain, lymphedema, osteoporosis, or neuropathy. If a certain topic is covered in one of the other modules, referral to the respective module is also given. Next to some basic tips on how to deal with these symptoms, participants are given advice to contact their physician or other health professional when they experience serious problems.

\section{Other website elements}

Personal page. On the Personal Page participants can find an overview of the personal advice they received from the screening questionnaire and the modules. Also the Personal Page contains a few instructional videos on how to use the KNW (see Fig. 4).

Video material. The use of videos is an important component of the KNW. Text messages accompanied with video are more appreciated and better recalled than text messages only [78, 79]. There are four types of videos implemented. First, instructional videos explain what participants can expect from the KNW and how they should navigate the program. Second, videos of fellow survivors were included for which we interviewed eight cancer survivors who were further along in their recovery process and willing to share their experiences of their life after cancer treatment and give advice to deal with certain issues. Since men and women interviewed were from different age groups and recovering from different types of cancer, it is more likely that participants identify with one of these role models. Third, videos of professionals were included for which we interviewed a sexologist and two clinical psychologists. These professionals give psychoeducation and advice from clinical practice. Fourth, with monthly news items participants were provided with extra information on specific areas. We interviewed

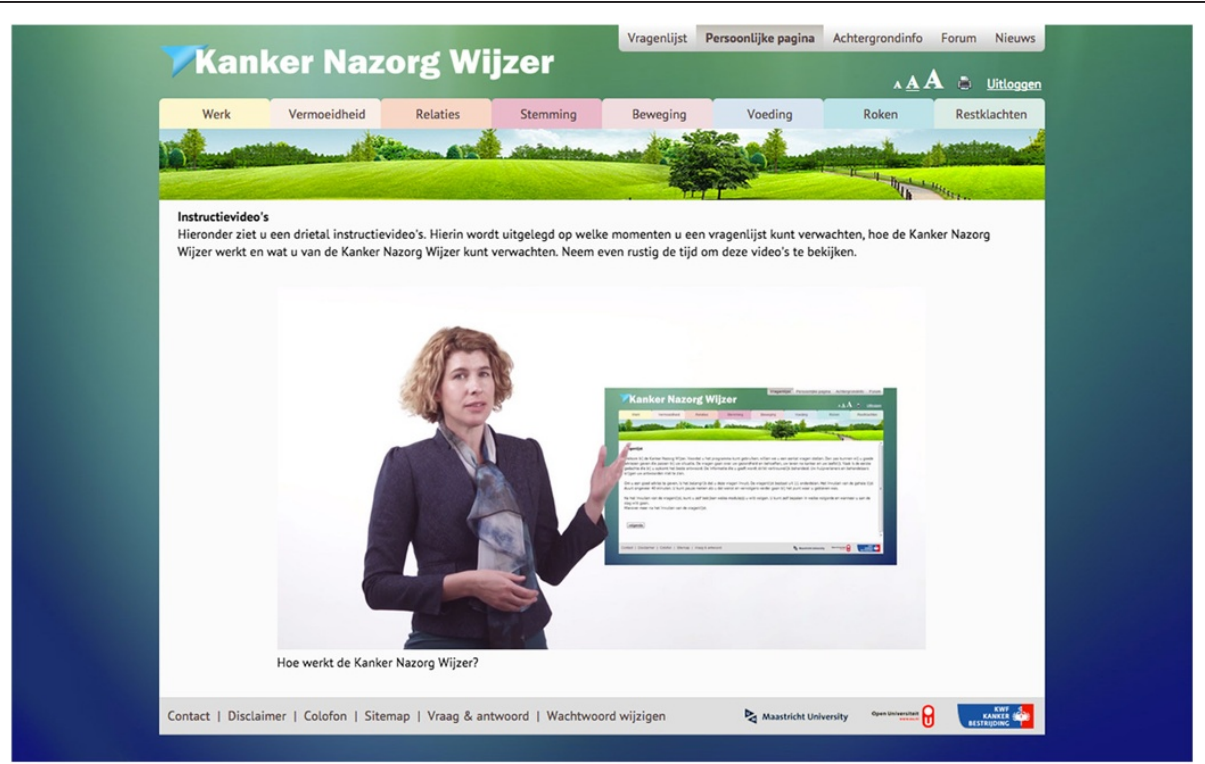

Fig. 4 Example of an instructional video explaining how to use the KNW 
professionals from different fields, talking about topics such as exercise, diet, return to work, anxiety and depression, lymphedema, and peer support groups. With these news items, we aim to keep the participants involved in the KNW by referring them to the module that is related to the topic discussed in the news item.

Forum. The KNW has a forum where fellow survivors can meet and ask each other or members of the KNW team questions. Participants are kept anonymous and the KNW team monitors the forum to control for advice contradicting the advice given in the modules.

\section{Pretesting and revising}

The KNW was pretested among 13 cancer survivors. In general, the appearance and content of the KNW was highly appreciated. The modules were evaluated positively $(M=7.6$, range $=1-10)$. Particularly, the videos of fellow survivors and professionals were highly rated $(M=8.0$, range $=1-10)$. The mean scores for understanding, usefulness, reliability, applicability, completeness, and appearance of the KNW ranged from 3.3 to 3.7 (range =1-4) and, therefore, were also highly appreciated. Some of the texts were evaluated as fairly long. Consequently, an editor reviewed and edited the text on readability and length. Furthermore, the tailored advice was evaluated to be of great value. While the tailored messages were computer generated, some participants initially thought that a person provided these messages. Although this demonstrated the power of tailoring, it also confused the participant when an answer did not fully match his or her expectations. Further, while the aim of the KNW is to stimulate participants to create their own solutions, some participants expected to receive personalized solutions to their problems. To address these issues, we included the previously mentioned instructional videos to explain how the KNW works and what participants can expect. After some final adjustments, the KNW was ready for implementation and effectiveness testing.

\section{Step 5: Adoption and implementation}

In the fifth step, a plan for program adoption and implementation was developed [29] in the context of testing the effectiveness of the KNW in a randomized controlled trial (RCT). We created a network with representatives (e.g. department heads, oncologists, research nurses, and nurse practitioners) from several hospitals' outpatient clinics in internal medicine, oncology, gynecology, urology, and the breast clinic. Forty-five hospitals in the Netherlands were contacted for assistance in the recruitment. Twenty-two hospitals agreed to participate, with 21 hospitals eventually participating in patient recruitment. Reasons for refusing participation included: hospital was already participating in other research projects, lack of time or excessive workload, too few staff members to recruit participants, or insufficient number of patients who met the inclusion criteria. Creating this network was a very time consuming process; it easily could take more than half a year from the moment of contacting a representative of a clinic until staff members began recruiting participants. Next, maintaining contact with multiple hospitals required good planning. To keep the staff members involved, we send out monthly newsletters with updates of the research project. Also, we regularly send thank-you cards. To conclude, timely planning of program adoption and implementation is essential.

\section{Step 6: Planning for evaluation}

In the final step, a plan for the effect and process evaluation of the intervention was developed. While the effect evaluation describes the differences in outcomes between the participants who were and were not exposed to the KNW, the process evaluation aims to get insight into the use and appreciation of the intervention [29]. For the evaluation of the KNW, an RCT comparing the intervention group with a waiting list control group was conducted. The RCT is approved by the Medical Ethics Committee of the Atrium Medical Centre (NL41445.096.12) and is registered in the Dutch Trial Register (NTR3375).

\section{Participants}

Patients were eligible for participation if they were 18 years or older, they had been diagnosed with any cancer type, primary treatment (surgery, chemotherapy, and/or radiotherapy) had been completed successfully for at least 6 weeks but no more than 52 weeks, there was no sign of recurrence in the latest follow-up visit, they were able to read and speak Dutch, and there was no serious medical, psychiatric, or cognitive illness that would interfere with participation. Computer literacy was not an explicit inclusion criterion, since the hospital staff was not able to screen for this. We expected that patients who were not computer literate would not participate in the study.

\section{Design and procedure}

Staff members of 21 hospitals (see Step 5) recruited patients from November 2013 through June 2014. The recruitment period varied per hospital. Patients were selected either during follow-up visits to the hospital or from reviews of patients' files. Oncologists, research nurses, and nurse practitioners from the outpatient clinics internal medicine, oncology, gynecology, urology, and breast clinics invited patients who met the inclusion criteria to participate by giving them an information package during a follow-up visit or sending the package 
to them following review of the patient's files. The information package included: (1) a letter with trial information and a username and password for first login, (2) an informed consent form with return envelope, (3) an information brochure concerning Medical Research, (4) a short manual on how to use the KNW, and (5) a small card with contact details and space where participants could write down their new username and password. A reminder was send after two weeks. Patients who agreed to participate were requested to sign the informed consent form and return it to the Open University of the Netherlands. Patients who participated in the research but did not return the consent form were contacted to do so. If they did not return the informed consent after several reminders, they were excluded from evaluation.

After online registration participants were randomly assigned to either the intervention group or the waiting list control group. Both groups had to fill in a questionnaire at four time points: At baseline (T0), after three months (T1), after six months (T2), and after 12 months (T3). T1 aimed to measure possible mediating variables, while T2 and T3 aimed to measure the short- and longterm effectiveness of the intervention respectively. The intervention group had six months access to the KNW directly after baseline. The waiting list control group had access to the intervention after T3.

Several methods were used to increase the response rate. First, several automated e-mail reminders were sent for each measurement. Second, in the baseline measurement, participants could leave their telephone number so we could contact them concerning the research. When we noted that participants had not reacted to the e-mail reminders, we contacted them through telephone as a final reminder. Third, in the e-mail reminders participants were explained that they would receive a small token of appreciation at the end of the trial. That is, participants received a book voucher with a value of $€ 10$ for trial participation.

\section{Measurements}

The primary outcomes for the evaluation of the KNW comprise psychosocial well-being and lifestyle outcomes. Measuring psychosocial well-being comprised assessment of quality of life [80] psychological distress [81, 82], mental adjustment to cancer [83], fatigue [84], work limitations [85-87], and social support [88]. Measuring lifestyle comprised assessment of physical activity [89], food consumption [90], and smoking behavior [91]. Secondary outcomes included measures that were assumed to moderate or mediate the effects of the primary outcomes, such as resilience [92], self-control [93], personal control [94], problem-solving skills $[95,96]$, and several background characteristics (e.g., age, gender, education, employment status, and disease and treatment history). Finally, we measured cancer survivors' unmet needs [97].

\section{Power calculation}

Sample size calculations were based on the outcomes of quality of life and psychological distress, since these were expected to be the most difficult to change. Calculations showed that 144 patients per group were required to compare means for these outcomes between groups with a power greater than .80 , one sided with an alpha of 0.05 . This was based on an expected effect size of .30 and, since recruitment would be through hospitals, a correction for multilevel analyses (intracluster correlation coefficient $=.005$, design effect $=1.15$ ). With an expected dropout rate of $20 \%$ during the study, this meant 376 patients needed to be included at baseline. With 231 patients included in the intervention group and 231 patients in the waiting list control group at baseline, this target has been achieved.

\section{Discussion}

The aim of this paper was to describe the systematic development and the study design for evaluation of the KNW, a web-based computer tailored intervention aimed at providing psychosocial and lifestyle support during life after cancer. The intervention aims to reduce cancer survivors' experienced problems in seven areas: (1) cancer-related fatigue, (2) difficulties concerning return to work, (3) anxiety and depression, (4) relationships and intimacy issues, (5) a lack of physical activity, (6) a lack of healthy food intake, and (7) difficulties in preparing or maintaining smoking cessation. By reducing the experienced problems in these areas, it is expected that this ultimately will result in a higher quality of life. The intervention was developed using the IM protocol [29]. This protocol supports health promotion program planners in systematically developing a theory and evidence-based program, and, as a result, increasing the likelihood of its effectiveness.

Beside the systematic development, the KNW has several other strengths. First, since the KNW concerns a web-based intervention, it can reach many patients at once and is accessible anytime and anywhere [28]. Second, by means of tailoring, information is more personally relevant. Therefore, it is more likely that this information increases attention, is more thoughtfully processed, and facilitates behavior change or maintenance $[43,44,49,50]$. Third, the use of video material to accompany the text also increases the likelihood that the information is remembered and recalled [78, 79]. Fourth, as universal methods, the KNW uses the principles of PST [54] and CBT [55] to stimulate cancer survivors to learn selfmanagement techniques that they also can apply in other situations. Fifth, elements of the KNW are based on 
existing interventions that already have been proven effective. Sixth, by evaluating the KNW through an RCT, we will be able to draw conclusions of the intervention's effectiveness.

However, there are also some weaknesses that should be mentioned. First, the intervention contains much written information. Since PST and CBT are quite extensive forms of therapy, it was a challenge to reduce the amount of information while still holding to the theoretical framework of these methods. Much information might particularly be a problem for people with low health literacy [98], since they might not be able to adequately process all the information given. To avoid an overload of information, participants could freely choose which modules to visit, which steps to follow, and which assignments to make. Participants could stop anytime and continue at the point where they stopped. The use of video material might also be beneficial in the understanding of the information for survivors with low health literacy $[99,100]$. Second, although the KNW is based on PST and CBT, there is no real patient-therapist interaction. Except by self-report, it is not possible to investigate whether the learned skills were applied in the right way [101]. In addition, it is difficult to anticipate the experienced emotions and non-verbal behavior of the participant or to give further explanation on why a certain advice is given. With computer tailoring, it is only possible to anticipate reactions that are highly expected. Third, while a greater proportion of cancer survivors are elderly [1], this group in general has fewer computer skills [102] and is less likely to use the Internet as a source for health-related information [24] than younger cancer survivors. To address this problem, the KNW was developed in such way that it is relatively easy to use. The invitation for participation was accompanied with a quick guide for using the KNW and the program provides instructional videos explaining how the KNW works. Also, support through telephone and e-mail is provided. It should be noted that this is only a temporary issue, as computer skills and use are increasing rapidly, especially among older adults [103].

In conclusion, the KNW is a theory and evidence based web-based computer tailored intervention that seems a promising tool to support cancer survivors to cope with cancer-related issues during life after treatment. The results of the RCT, which will be presented in other papers, will provide more insight into the effectiveness and working mechanisms of the KNW and its appreciation by its users.

\section{Abbreviations}

KNW: Kanker Nazorg Wijzer (Cancer Aftercare Guide); IM: Intervention Mapping; POs: Performance objectives; COs: Change objectives; PST: Problem-Solving Therapy; CBT: Cognitive Behavioral Therapy; RCT: Randomized Controlled Trial.

\section{Competing interests}

The authors declare that they have no competing interests.

\section{Authors' contributions}

$L L, C B$, and $I M$ designed and wrote the original proposal. RW, $A B$, and IK were responsible for the writing and programming of the intervention content. $L L, C B$, and $I M$ critically reviewed and approved the intervention content. $A B$ had the leading role in the recruitment procedure. RW was responsible for drafting the manuscript. All authors contributed to the writing of the manuscript and critically revised the manuscript for important intellectual content. All authors read and approved the final manuscript.

\section{Acknowledgements}

This study is funded by the Dutch Cancer Society (grant number NOU2011-5151). The authors would like to sincerely thank all the hospitals who helped with the recruitment of the participants: Atrium Medical Centre (Heerlen), Beatrix Hospital (Gorinchem), Bernhoven Hospital (Uden), Bronovo Hospital (Den Haag), Catharina Hospital (Eindhoven), Diakonessenhuis (Utrecht), Elkerliek Hospital (Helmond), Flevo Hospital (Almere), IJsselland Hospital (Capelle aan den IJssel), Ikazia Hospital (Rotterdam), LangeLand Hospital (Zoetermeer), Laurentius Hospital (Roermond), Lievensberg Hospital (Bergen op Zoom), Maasstad Hospital (Rotterdam), Maastricht UMC+ (Maastricht), Orbis Medical Centre (Sittard-Geleen), Slingeland Hospital (Doetinchem), Spaarne Hospital (Hoofddorp), St. Anna Hospital (Geldrop), St. Jans Gasthuis (Weert), and VieCuri Medical Centre (Venlo). Our thanks to the cancer survivors who tested the intervention, to the interviewed survivors who were willing to tell their experiences on camera, and to the professionals who participated in the video interviews. Finally, our thanks to Linda Küsters for her contribution in setting up the preliminary studies and her contribution in the development of the Diet and Smoking modules, to Rianne Golsteijn for the adaption and integration of the Active Plus intervention, and to Mieke Fiers for critically reviewing and editing the intervention messages to make them more comprehensive for the users of the program.

\section{Author details}

${ }^{1}$ Faculty of Psychology and Educational Sciences, Open University of the Netherlands, P.O. Box 2960, 6401 DL Heerlen, The Netherlands. ${ }^{2}$ CAPHRI School for Public Health and Primary Care, Maastricht University, P.O. Box 616, 6200 MD Maastricht, The Netherlands.

Received: 17 June 2015 Accepted: 30 July 2015

Published online: 11 August 2015

\section{References}

1. The Dutch Cancer Society. Kanker in Nederland tot 2020: trends en prognoses [Cancer in the Netherlands up to 2020: trends and prognoses]. Amsterdam: KWF Kankerbestrijding; 2011.

2. Mehnert A, Koch U. Psychological comorbidity and health-related quality of life and its association with awareness, utilization, and need for psychosocial support in a cancer register-based sample of long-term breast cancer survivors. J Psychosom Res. 2008;64(4):383-91. doi:10.1016/ j.jpsychores.2007.12.005.

3. Simard S, Thewes B, Humphris G, Dixon M, Hayden C, Mireskandari S, et al. Fear of cancer recurrence in adult cancer survivors: a systematic review of quantitative studies. J Canc Surviv. 2013;7(3):300-22. doi:10.1007/s11764-013-0272-z.

4. Prue G, Rankin J, Allen J, Gracey J, Cramp F. Cancer-related fatigue: a critical appraisal. Eur J Cancer. 2006;42(7):846-63. doi:10.1016/j.ejca.2005.11.026.

5. Duijts SF, van Egmond MP, Spelten E, van Muijen P, Anema JR, van der Beek AJ. Physical and psychosocial problems in cancer survivors beyond return to work: a systematic review. Psychooncology. 2014;23(5):481-92. doi:10.1002/pon.3467.

6. Kattlove H, Winn RJ. Ongoing care of patients after primary treatment for their cancer. CA Cancer J Clin. 2003;53(3):172-96. doi:10.3322/ canjclin.53.3.172.

7. Valdivieso M, Kujawa AM, Jones T, Baker LH. Cancer survivors in the United States: a review of the literature and a call to action. Int J Med Sci. 2012;9(2):163-73. doi:10.7150/ijms.3827.

8. Harrington CB, Hansen JA, Moskowitz M, Todd BL, Feuerstein M. It's not over when it's over: long-term symptoms in cancer survivors-a systematic 
review. Int'l J Psychiatry in Medicine. 2010;40(2):163-81. doi:10.2190/ PM.40.2.C.

9. Wu HS, Harden JK. Symptom burden and quality of life in survivorship: a review of the literature. Cancer Nurs. 2015;38(1):E29-54. doi:10.1097/ NCC.0000000000000135.

10. Foster C, Wright D, Hill H, Hopkinson J, Roffe L. Psychosocial implications of living 5 years or more following a cancer diagnosis: a systematic review of the research evidence. Eur J Cancer Care (Engl). 2009;18(3):223-47. doi:10.1111/j.1365-2354.2008.01001.x.

11. Hinnen C, Ranchor AV, Sanderman R, Snijders TA, Hagedoorn M, Coyne JC. Course of distress in breast cancer patients, their partners, and matched control couples. Ann Behav Med. 2008;36(2):141-8. doi:10.1007/s12160-008-9061-8.

12. Mayer DK, Terrin NC, Menon U, Kreps GL, McCance K, Parsons SK, et al. Health behaviors in cancer survivors. Oncol Nurs Forum. 2007;34(3):643-51. doi:10.1188/07.0NF.643-651.

13. Inoue-Choi M, Robien $\mathrm{K}$, Lazovich D. Adherence to the WCRF/AICR guidelines for cancer prevention is associated with lower mortality among older female cancer survivors. Cancer Epidemiol Biomarkers Prev. 2013;22(5):792-802. doi:10.1158/1055-9965.EPI-13-0054.

14. LeMasters TJ, Madhavan SS, Sambamoorthi U, Kurian S. Health behaviors among breast, prostate, and colorectal cancer survivors: a US populationbased case-control study, with comparisons by cancer type and gender. J Cancer Surviv. 2014;8(3):336-48. doi:10.1007/s11764-014-0347-5.

15. Bellizzi KM, Rowland JH, Jeffery DD, McNeel T. Health behaviors of cancer survivors: examining opportunities for cancer control intervention. J Clin Oncol. 2005;23(34):8884-93. doi:10.1200/JCO.2005.02.2343.

16. Williams K, Steptoe A, Wardle J. Is a cancer diagnosis a trigger for health behaviour change? Findings from a prospective, population-based study. $\mathrm{Br}$ J Cancer. 2013;108(11):2407-12. doi:10.1038/bjc.2013.254.

17. Hodgkinson K, Butow P, Fuchs A, Hunt GE, Stenlake A, Hobbs KM, et al. Long-term survival from gynecologic cancer: psychosocial outcomes, supportive care needs and positive outcomes. Gynecol Oncol. 2007;104(2):381-9. doi:10.1016/j.ygyno.2006.08.036.

18. Hodgkinson K, Butow P, Hunt GE, Pendlebury S, Hobbs KM, Wain G. Breast cancer survivors' supportive care needs $2-10$ years after diagnosis. Support Care Cancer. 2007:15(5):515-23. doi:10.1007/s00520-006-0170-2.

19. Smith $A B$, King M, Butow P, Luckett $T$, Grimison $P$, Toner $G C$, et al. The prevalence and correlates of supportive care needs in testicular cancer survivors: a cross-sectional study. Psychooncology. 2013;22(11):2557-64. doi:10.1002/pon.3323.

20. Willems RA, Bolman CAW, Mesters I, Kanera IM, Beaulen AAJM, Lechner L. Cancer survivors in the first year after treatment: the prevalence and correlates of unmet needs in different domains. Psychooncology. 2015. doi:10.1002/pon.3870.

21. James-Martin G, Koczwara B, Smith EL, Miller MD. Information needs of cancer patients and survivors regarding diet, exercise and weight management: a qualitative study. Eur J Cancer Care (Engl). 2014;23(3):340-8. doi:10.1111/ecc.12159.

22. Pullar JM, Chisholm A, Jackson C. Dietary information for colorectal cancer survivors: an unmet need. N Z Med J. 2012;125(1356):27-37.

23. Vereniging van Integrale Kankercentra. Herstel na kanker: landelijke richtlijn [Recovery after cancer: national guideline]. Utrecht: Vereniging van Integrale Kankercentra; 2011.

24. Chou WY, Liu B, Post S, Hesse B. Health-related Internet use among cancer survivors: data from the Health Information National Trends Survey, 2003-2008. J Cancer Surviv. 2011;5(3):263-70. doi:10.1007/ s11764-011-0179-5.

25. Warren E, Footman K, Tinelli M, McKee M, Knai C. Do cancer-specific websites meet patient's information needs? Patient Educ Couns. 2014;95(1):126-36. doi:10.1016/j.pec.2013.12.013.

26. Mayer DK, Terrin NC, Kreps GL, Menon U, McCance K, Parsons SK, et al. Cancer survivors information seeking behaviors: a comparison of survivors who do and do not seek information about cancer. Patient Educ Couns. 2007:65(3):342-50. doi:10.1016/j.pec.2006.08.015.

27. Leykin Y, Thekdi SM, Shumay DM, Munoz RF, Riba M, Dunn LB. Internet interventions for improving psychological well-being in psycho-oncology: review and recommendations. Psychooncology. 2012;21(9):1016-25. doi:10.1002/pon.1993.

28. Lustria ML, Cortese J, Noar SM, Glueckauf RL. Computer-tailored health interventions delivered over the web: review and analysis of key components. Patient Educ Couns. 2009;74(2):156-73. doi:10.1016/.jpec.2008.08.023.
29. Bartholomew LK, Parcel GS, Kok G, Gottlieb NH, Fernández ME. Planning health promotion programs: an intervention mapping approach. 3rd ed. San Francisco: Jossey-Bass; 2011.

30. Rutten LJ, Arora NK, Bakos AD, Aziz N, Rowland J. Information needs and sources of information among cancer patients: a systematic review of research (1980-2003). Patient Educ Couns. 2005;57(3):250-61. doi:10.1016/ j.pec.2004.06.006.

31. Brown LF, Kroenke K, Theobald DE, Wu J, Tu W. The association of depression and anxiety with health-related quality of life in cancer patients with depression and/or pain. Psychooncology. 2010;19(7):734-41. doi:10.1002/pon.1627.

32. Irwin MR, Olmstead RE, Ganz PA, Haque R. Sleep disturbance, inflammation and depression risk in cancer survivors. Brain Behav Immun. 2013;30(Suppl):S58-67. doi:10.1016/j.bbi.2012.05.002.

33. Paice JA. Chronic treatment-related pain in cancer survivors. Pain. 2011;152(3):S84-9. doi:10.1016/.jpain.2010.10.010.

34. Chung E, Brock G. Sexual rehabilitation and cancer survivorship: a state of art review of current literature and management strategies in male sexual dysfunction among prostate cancer survivors. J Sex Med. 2013;10 Suppl 1:102-11. doi:10.1111/j.1743-6109.2012.03005.x.

35. Lammerink EA, de Bock GH, Pras E, Reyners AK, Mourits MJ. Sexual functioning of cervical cancer survivors: a review with a female perspective. Maturitas. 2012;72(4):296-304. doi:10.1016/j.maturitas.2012.05.006.

36. Aleksandrova K, Pischon T, Jenab M, Bueno-de-Mesquita HB, Fedirko V, Norat $\mathrm{T}$, et al. Combined impact of healthy lifestyle factors on colorectal cancer: a large European cohort study. BMC Med. 2014;12(1):168. doi:10.1186/s12916-014-0168-4.

37. Petersen KE, Johnsen NF, Olsen A, Albieri V, Olsen LK, Dragsted LO, et al. The combined impact of adherence to five lifestyle factors on all-cause, cancer and cardiovascular mortality: a prospective cohort study among Danish men and women. Br J Nutr. 2015;113(5):849-58. doi:10.1017/ S0007114515000070

38. Baena Ruiz R, Salinas HP. Diet and cancer: risk factors and epidemiological evidence. Maturitas. 2014;77(3):202-8. doi:10.1016/..maturitas.2013.11.010.

39. Schmid D, Leitzmann MF. Association between physical activity and mortality among breast cancer and colorectal cancer survivors: a systematic review and meta-analysis. Ann Oncol. 2014;25(7):1293-311. doi:10.1093/ annonc/mdu012.

40. Rock CL, Doyle C, Demark-Wahnefried W, Meyerhardt J, Courneya KS, Schwartz AL, et al. Nutrition and physical activity guidelines for cancer survivors. CA Cancer J Clin. 2012;62(4):243-74. doi:10.3322/caac.21142.

41. Morgan DL, Krueger RA. Focus group kit. Thousand Oaks: SAGE Publications; 1998.

42. Kanera IM, Bolman CAW, Willems RA, Mesters I, Beaulen AAJM, Geurts JMJ, et al. Abstracts from the ICBM 2014 Meeting: The contribution of behavioural, cancer-related and psychological determinants to health behaviours of cancer survivors. Int J Behav Med. 2014;21 Suppl 1:1-216. doi:10.1007/s12529-014-9418-2.

43. Noar SM, Benac CN, Harris MS. Does tailoring matter? Meta-analytic review of tailored print health behavior change interventions. Psychol Bull. 2007;133(4):673-93. doi:10.1037/0033-2909.133.4.673.

44. De Vries H, Brug J. Computer-tailored interventions motivating people to adopt health promoting behaviours: introduction to a new approach. Patient Educ Couns. 1999;36(2):99-105. doi:10.1016/s0738-3991(98)00127-x.

45. De Nooijer J, Lechner L, Candel M, de Vries H. Short- and long-term effects of tailored information versus general information on determinants and intentions related to early detection of cancer. Prev Med. 2004;38(6):694-703. doi:10.1016/j.ypmed.2003.12.016.

46. Kuijpers W, Groen WG, Aaronson NK, van Harten WH. A systematic review of web-based interventions for patient empowerment and physical activity in chronic diseases: relevance for cancer survivors. J Med Internet Res. 2013;15(2):e37. doi:10.2196/jmir.2281.

47. Oenema A, Brug J, Dijkstra A, de Weerdt I, de Vries H. Efficacy and use of an internet-delivered computer-tailored lifestyle intervention, targeting saturated fat intake, physical activity and smoking cessation: a randomized controlled trial. Ann Behav Med. 2008;35(2):125-35. doi:10.1007/s12160-008-9023-1.

48. Peels DA, Bolman C, Golsteijn RH, de Vries H, Mudde AN, van Stralen MM, et al. Long-term efficacy of a printed or a web-based tailored physical activity intervention among older adults. Int J Behav Nutr Phys Act. 2013;10:104. doi:10.1186/1479-5868-10-104. 
49. Rimal RN, Adkins AD. Using computers to narrowcast health messages: the role of audience segmentation, targeting, and tailoring in health promotion. In: Thompson TL, Dorsey AM, Miller Kl, Parrott R, editors. Handbook of health communication. Mahwah: Lawrence Erlbaum Associates; 2003. p. 497-513.

50. Brug J, Oenema A, Campbell M. Past, present, and future of computer-tailored nutrition education. Am J Clin Nutr. 2003;77(4):1028S-34S.

51. Clark NM. Management of chronic disease by patients. Annu Rev Public Health. 2003;24:289-313. doi:10.1146/annurev.publhealth.24.100901.141021.

52. Scheier MF, Carver CS. Goals and confidence as self-regulatory elements underlying health and illness behavior. In: Cameron LD, Leventhal H, editors. The self-regulation of health and illness behaviour. New York: Routledge; 2003. p. 17-41.

53. D'Zurilla TJ, Nezu AM. Problem-solving therapy: a positive approach to clinical intervention. 3rd ed. New York: Springer Publishing Company; 2007.

54. Nezu AM, Nezu CM, Houts PS, Friedman SH, Faddis S. Relevance of problem-solving therapy to psychosocial oncology. J Psychosoc Oncol. 1999;16(3-4):5-26. doi:10.1300/J077v16n03_02.

55. Bleijenberg G, Gielissen M, Berends T, Voskamp H, Bazelmans E, Verhagen S. Cognitive behaviour therapy for post-cancer fatigue: a treatment protocol. In: Gielissen MFM. Fatigue in cancer survivors: from assessment to cognitive behaviour therapy (Doctoral dissertation). Nijmegen: Radboud University; 2007. p. 35-49.

56. Doorenbos A, Given B, Given C, Verbitsky N, Cimprich B, McCorkle R. Reducing symptom limitations: a cognitive behavioral intervention randomized trial. Psychooncology. 2005;14(7):574-84. doi:10.1002/pon.874.

57. Mishel MH, Belyea M, Germino BB, Stewart JL, Bailey Jr DE, Robertson C, et al. Helping patients with localized prostate carcinoma manage uncertainty and treatment side effects: nurse-delivered psychoeducational intervention over the telephone. Cancer. 2002;94(6):1854-66. doi:10.1002/ cncr.10390.

58. Fors EA, Bertheussen GF, Thune I, Juvet LK, Elvsaas IK, Oldervoll $L$, et al. Psychosocial interventions as part of breast cancer rehabilitation programs? Results from a systematic review. Psychooncology. 2011;20(9):909-18. doi:10.1002/pon.1844.

59. Allen SM, Shah AC, Nezu AM, Nezu CM, Ciambrone D, Hogan J, et al. A problem-solving approach to stress reduction among younger women with breast carcinoma: a randomized controlled trial. Cancer. 2002;94(12):3089-100. doi:10.1002/cncr.10586.

60. Goedendorp MM, Gielissen MF, Peters ME, Verhagen CA, Bleijenberg G. Moderators and long-term effectiveness of cognitive behaviour therapy for fatigue during cancer treatment. Psychooncology. 2012;21(8):877-85. doi:10.1002/pon.1981.

61. Heins MJ, Knoop H, Burk WJ, Bleijenberg G. The process of cognitive behaviour therapy for chronic fatigue syndrome: which changes in perpetuating cognitions and behaviour are related to a reduction in fatigue? J Psychosom Res. 2013;75(3):235-41. doi:10.1016/ j.jpsychores.2013.06.034.

62. Goedendorp MM, Gielissen MF, Verhagen CA, Bleijenberg G. Psychosocial interventions for reducing fatigue during cancer treatment in adults. Cochrane Database Syst Rev. 2009;1:CD006953. doi:10.1002/ 14651858.CD006953.pub2.

63. Garland SN, Johnson JA, Savard J, Gehrman P, Perlis M, Carlson L, et al. Sleeping well with cancer: a systematic review of cognitive behavioral therapy for insomnia in cancer patients. Neuropsychiatr Dis Treat. 2014;10:1113-24. doi:10.2147/NDT.S47790.

64. Osborn RL, Demoncada AC, Feuerstein M. Psychosocial interventions for depression, anxiety, and quality of life in cancer survivors: meta-analyses. Int J Psychiatry Med. 2006;36(1):13-34. doi:10.2190/eufn-rv1k-y3tr-fk0l.

65. Nezu AM, Nezu CM, Felgoise SH, McClure KS, Houts PS. Project Genesis: assessing the efficacy of problem-solving therapy for distressed adult cancer patients. J Consult Clin Psychol. 2003;71(6):1036-48. doi:10.1037/0022-006X.71.6.1036.

66. Van Stralen MM, Kok G, de Vries H, Mudde AN, Bolman C, Lechner L. The Active plus protocol: systematic development of two theory- and evidence-based tailored physical activity interventions for the over-fifties. BMC Public Health. 2008;8:399. doi:10.1186/1471-2458-8-399.

67. Van Stralen MM, de Vries H, Mudde AN, Bolman C, Lechner L. Efficacy of two tailored interventions promoting physical activity in older adults. Am J Prev Med. 2009;37(5):405-17. doi:10.1016/j.amepre.2009.07.009.

68. Peels DA, van Stralen MM, Bolman C, Golsteijn RH, de Vries H, Mudde AN, et al. Development of web-based computer-tailored advice to promote physical activity among people older than 50 years. J Med Internet Res. 2012;14(2):e39. doi:10.2196/jmir.1742.

69. Peels DA, van Stralen MM, Bolman C, Golsteijn RH, de Vries H, Mudde AN, et al. The differentiated effectiveness of a printed versus a web-based tailored physical activity intervention among adults aged over 50 . Health Educ Res. 2014;29(5):870-82. doi:10.1093/her/cyu039.

70. Van Berkel TFM. Smoking cessation as secondary prevention for patients with coronary artery disease (Doctoral dissertation). Rotterdam: Erasmus University; 2000.

71. Te Poel F, Bolman C, Reubsaet A, de Vries H. Efficacy of a single computer-tailored e-mail for smoking cessation: results after 6 months. Health Educ Res. 2009;24(6):930-40. doi:10.1093/her/cyp036.

72. Stanczyk NE, Bolman C, Muris JW, de Vries H. Study protocol of a Dutch smoking cessation e-health program. BMC Public Health. 2011;11:847. doi:10.1186/1471-2458-11-847.

73. Oenema A, Brug J, Lechner L. Web-based tailored nutrition education: results of a randomized controlled trial. Health Educ Res. 2001;16(6):647-60. doi:10.1093/her/16.6.647.

74. Van Keulen HM, Mesters I, Brug J, Ausems M, Campbell M, Resnicow K, et al. Vitalum study design: RCT evaluating the efficacy of tailored print communication and telephone motivational interviewing on multiple health behaviors. BMC Public Health. 2008;8:216. doi:10.1186/1471-2458-8-216.

75. Van Keulen HM. Vitalum: development and evaluation of tailored print communication and telephone motivational interviewing to improve lifestyle behaviors among older adults (Doctoral dissertation). Maastricht: Maastricht University; 2010.

76. Walthouwer MJ, Oenema A, Soetens K, Lechner L, de Vries H. Systematic development of a text-driven and a video-driven web-based computertailored obesity prevention intervention. BMC Public Health. 2013;13:978. doi:10.1186/1471-2458-13-978.

77. Springvloet L, Lechner L, Oenema A. Planned development and evaluation protocol of two versions of a web-based computer-tailored nutrition education intervention aimed at adults, including cognitive and environmental feedback. BMC Public Health. 2014;14:47. doi:10.1186/1471-2458-14-47.

78. Bol N, Smets EM, Rutgers MM, Burgers JA, de Haes HC, Loos EF, et al. Do videos improve website satisfaction and recall of online cancer-related information in older lung cancer patients? Patient Educ Couns. 2013;92(3):404-12. doi:10.1016/j.pec.2013.06.004.

79. Idriss NZ, Alikhan A, Baba K, Armstrong AW. Online, video-based patient education improves melanoma awareness: a randomized controlled trial. Telemed J E Health. 2009;15(10):992-7. doi:10.1089/tmj.2009.0055.

80. Aaronson NK, Ahmedzai S, Bergman B, Bullinger M, Cull A, Duez NJ, et al. The European Organization for Research and Treatment of Cancer QLQ-C30: a quality-of-life instrument for use in international clinical trials in oncology. JNCI J Natl Cancer Inst. 1993;85(5):365-76. doi:10.1093/jnci/85.5.365.

81. Zigmond AS, Snaith RP. The hospital anxiety and depression scale. Acta Psychiatr Scand. 1983;67(6):361-70. doi:10.1111/j.1600-0447.1983.tb09716.x.

82. Bjelland I, Dahl AA, Haug TT, Neckelmann D. The validity of the Hospital Anxiety and Depression Scale. An updated literature review. J Psychosom Res. 2002;52(2):69-77. doi:10.1016/s0022-3999(01)00296-3.

83. Watson M, Homewood J. Mental Adjustment to Cancer Scale: psychometric properties in a large cancer cohort. Psychooncology. 2008;17(11):1146-51. doi:10.1002/pon.1345.

84. Vercoulen JH, Swanink CM, Fennis JF, Galama JM, van der Meer JW, Bleijenberg G. Dimensional assessment of chronic fatigue syndrome. J Psychosom Res. 1994;38(5):383-92. doi:10.1016/0022-3999(94)90099-x.

85. Lerner D, Amick III BC, Rogers WH, Malspeis S, Bungay K, Cynn D. The Work Limitations Questionnaire. Med Care. 2001;39(1):72-85. doi:10.1097/ 00005650-200101000-00009.

86. Burton WN, Pransky G, Conti DJ, Chen CY, Edington DW. The association of medical conditions and presenteeism. J Occup Environ Med. 2004;46(6):S38-45. doi:10.1097/01.jom.0000126687.49652.44.

87. Burton WN, Chen CY, Conti DJ, Pransky G, Edington DW. Caregiving for ill dependents and its association with employee health risks and productivity. J Occup Environ Med. 2004;46(10):1048-56. doi:10.1097/ 01.jom.0000141830.72507.32

88. Van Sonderen E. Het meten van sociale steun met de Sociale Steun LijstInteracties (SSL-I) en Sociale Steun Lijst-Discrepanties (SSL-D): een handleiding [Measuring social support with the Social Support List-Interactions (SSL-I) and Social Support List-Discrepanties (SSL-D): a manual]. 2nd ed. Noordelijk Centrum voor Gezondheidsvraagstukken: Groningen; 2012. 
89. Wendel-Vos GC, Schuit AJ, Saris WH, Kromhout D. Reproducibility and relative validity of the short questionnaire to assess health-enhancing physical activity. J Clin Epidemiol. 2003;56(12):1163-9. doi:10.1016/s0895-4356(03)00220-8.

90. Van den Brink CL, Ocke MC, Houben AW, van Nierop P, Droomers M. Validering van standaardvraagstelling voeding voor Lokale en Nationale Monitor Volksgezondheid [Validation of a Community Health Services food consumption questionnaire in the Netherlands]. RIVM: Bilthoven; 2005.

91. Mudde AN, Willemsen MC, Kremers S, de Vries H. Meetinstrumenten voor onderzoek naar stoppen met roken [Measurement instruments for research on smoking cessation]. STIVORO: Den Haag; 2006.

92. Smith BW, Dalen J, Wiggins K, Tooley E, Christopher P, Bernard J. The brief resilience scale: assessing the ability to bounce back. Int J Behav Med. 2008;15(3):194-200. doi:10.1080/10705500802222972.

93. Tangney JP, Baumeister RF, Boone AL. High self-control predicts good adjustment, less pathology, better grades, and interpersonal success. J Pers. 2004;72(2):271-324. doi:10.1111/j.0022-3506.2004.00263.x.

94. Moss-Morris R, Weinman J, Petrie K, Horne R, Cameron L, Buick D. The Revised Illness Perception Questionnaire (IPQ-R). Psychol Health. 2002;17(1):1-16. doi:10.1080/08870440290001494.

95. D'Zurilla TJ, Nezu AM, Maydeu-Olivares A. Social Problem-Solving Inventory-Revised (SPSI-R). Multi-Health Systems: Tonawanda; 2002.

96. Dreer LE, Berry J, Rivera P, Snow M, Elliott TR, Miller D, et al. Efficient assessment of social problem-solving abilities in medical and rehabilitation settings: a Rasch analysis of the Social Problem-Solving Inventory-Revised. J Clin Psychol. 2009;65(7):653-69. doi:10.1002/jclp.20573.

97. Hodgkinson K, Butow P, Hunt GE, Pendlebury S, Hobbs KM, Lo SK, et al. The development and evaluation of a measure to assess cancer survivors' unmet supportive care needs: the CaSUN (Cancer Survivors' Unmet Needs measure). Psychooncology. 2007;16(9):796-804. doi:10.1002/pon.1137.

98. Verkissen MN, Ezendam NP, Fransen MP, Essink-Bot ML, Aarts MJ, Nicolaije $K A$, et al. The role of health literacy in perceived information provision and satisfaction among women with ovarian tumors: a study from the population-based PROFILES registry. Patient Educ Couns. 2014;95(3):421-8. doi:10.1016/j.pec.2014.03.008.

99. Hart TL, Blacker S, Panjwani A, Torbit L, Evans M. Development of multimedia informational tools for breast cancer patients with low levels of health literacy. Patient Educ Couns. 2015;98(3):370-7. doi:10.1016/j.pec.2014.11.015.

100. Davis TC, Williams MV, Marin E, Parker RM, Glass J. Health literacy and cancer communication. CA Cancer J Clin. 2002;52(3):134-49. doi:10.3322/ canjclin.52.3.134

101. Finfgeld DL. Computer-assisted therapy: harbinger of the 21 st century? Arch Psychiatr Nurs. 1999;13(6):303-10. doi:10.1016/s0883-9417(99)80062-4.

102. AGE Platform Europe. Media literacy, digital exclusion and older people. Brussels: AGE Platform Europe; 2008

103. Centraal Bureau voor de Statistiek. ICT gebruik van personen naar persoonskenmerken [ICT usage of persons by personal characteristics]. Den Haag: Centraal Bureau voor de Statistiek; 2014. http://statline.cbs.nl/Statweb/ publication/?WW=T\&DM=SLNL\&PA=71098ned\&D1=7-10,27-34,69-72,8591\&D2=3-6\&D3=0,\&HD=150601-1400\&HDR=G2,G1\&STB=T\&P=L. 2014. Accessed 1 June 2015.

\section{Submit your next manuscript to BioMed Central and take full advantage of:}

- Convenient online submission

- Thorough peer review

- No space constraints or color figure charges

- Immediate publication on acceptance

- Inclusion in PubMed, CAS, Scopus and Google Scholar

- Research which is freely available for redistribution

Submit your manuscript at www.biomedcentral.com/submit 